\title{
Collaborating with Alan Gross
}

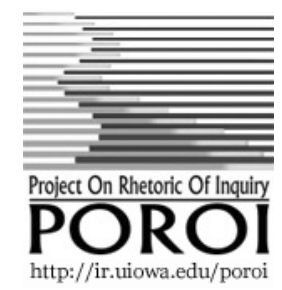

Arthur Walzer

University of Minnesota

Minneapolis, $M N$

Poroi 10,2 (December 2014)

I chaired the search committee in what was then the Department of Rhetoric (since eliminated) in the College of Agriculture at the University of Minnesota when the department hired Alan as an Associate Professor in 1991. At the time, Rhetoric was an anomaly in the university for having only an undergraduate major, and we were under administrative mandate to develop graduate programs typical of other units. Thus, the hiring of Alan at a senior level.

During the interview process, Alan mentioned the possibility of our collaborating. About a year later, our first collaboration (the subject of this essay) materialized. I remember it with some trepidation. I had an idea for an article-a critique of the analyses done by rhetoric scholars of the Challenger disaster. Though these scholars were known and respected as students of rhetoric, they appeared to me to eschew the assumptions of Aristotelian rhetoric in their analyses of the communication failures that contributed to the fatal decision to launch in unusually cold temperatures on 28 January 1986.

I decided to discuss my plans with Alan. I remember our discussion well, and with some trepidation. He was enthusiastic, very animated in our discussion of my ideas. But his creative intelligence was quicker and ran deeper than mine. On the one hand, he saw important implications that I had been unaware of; on the other hand, I feared he might hijack my ideas, which, no matter how modest, were mine. I began to back off; I felt I needed time to sort out what I wanted to say and to know better what was mine and what his. But it quickly became apparent that it was already too late for that possibility: I was unable or unwilling to segregate my ideas from his. Recognizing my dilemma, Alan proposed we each write our own essays, listing the other as second author. 
Alan produced his essay in a matter of days. He did in this case what he consistently does better than anyone else I know-deepen the significance of an idea and express it with a remarkable compression. Here is the first paragraph from his version of "our" essay:

There is widespread agreement with the Presidential Commission that the failure of the Challenger launch was mechanical and organizational. The natural inference is that what was needed were more resilient $\mathrm{O}$ rings, better-organized bureaucracies, clearer memos. There is an opposing view, the need, rather, for heightened cognitive and ethical awareness. It is not its complexity or subtlety that makes this latter view interesting; it is that a position so obvious has eluded so many intelligent investigators and scholars. We contend that the general failure of investigators and scholars is systemic, a common tendency to emphasize the technical and procedural aspects of organizational life at the expense of the cognitive and ethical, to emphasize rules over deliberations (Gross, 1997, 75). ${ }^{1}$

This paragraph is Alan's version of the conventional problem statement. For me, in my original thinking at least, the problem was rooted in an inner-disciplinary squabble about the appropriate theory to apply to a particular case. For Alan the problem is the general "systemic" displacement in modern life of the "cognitive and ethical" by the "mechanical and organizational." The grammatical parallelism of his noun pairs prefigures the rhetorical structure of his argument that follows. Furthermore, Alan's "more resilient O-rings, better organized bureaucracies, [and] clearer memos" function at several levels: the phrases constitute and introduce the evidence that will form the basis of his argument. But more importantly they function as metonyms that make material the "mechanical and organizational" perspective. As such these phrases prefigure by contrast a later metonym that stands for the "cognitive and ethical:" he managers from the Thiokol Chemical Corporation and NASA who ultimately ordered the launch, Alan maintains, should have first put themselves by act of ethical imagination "in the shoes" of the astronauts, traveled in their minds' eyes "the slippery walk-ways," confronted "the eighteen-inch icicles on the launch pad," and entered the capsule themselves (Gross, 1997, 85). That is the type of solidarity, he

${ }^{1}$ The other article, in which I was first author, is Walzer and Gross, 1994. 
posits, that ethical thinking requires. It is foreign to the "mechanical and organizational" mindset that is systemically rooted in modern bureaucracies. Compared to the predictable sludge that characterizes the conventional scene setting in a standard introduction to an academic article, Alan's introduction is remarkably compressed, dramatic, and transcendent.

The second paragraph in this essay is Alan's version of the conventional rationale-the need for the essay that follows.

The failure of communication scholars is particularly disturbing in view of their rhetorical training and perspective. Surely, if any work is rooted in a tradition that refuses to separate the technical and the procedural from the cognitive and ethical, rules from deliberations, that work is [Aristotle's] Rhetoric. According to some analysts, however, the deep history of the West is a story of decline, a decline in which rhetoric participates. The tendency of advanced capitalism to dissociate political, social, and economic arrangements from the lived experience of human communities infects us all with an anomie that robs our lives of meaning; analogously, the cause of rhetoric's specific anomie, its slow drift over the centuries from centrality to relative insignificance, is the erosion of the coherent and sustaining ethical and political tradition that gave it birth, a tradition further weakened by the cultural pluralism that characterizes most contemporary democracies (Gross, 1997, 75-6.)

Recall that in my original thoughts about my own essay, the rationale was the need for a sub-group of disciplinary scholars, namely, rhetoricians in communication and composition, to take seriously the epistemological implications of the perspective they claimed to embrace. Alan's version starts with this putative failure. But in his telling scholarly analyses of the Challenger explosion are not of particular interest in their own terms. What makes these failed analyses worthy of our attention is that they exemplify the split between the "technical and the procedural" on the one hand, and, on the other, the "cognitive and ethical." Facts from values. Alan then amplifies the implications of what is at issue: Rhetoric scholars unwittingly forward the decline of the West, contribute to an anomie that denies meaning to our lives, and further the decline of rhetoric itself as a meaningful discipline in modern life! We have moved from the obscure corner of academia where I placed the problem and rationale to 
the Zeitgeist. Okay, the move is over the top. But the essential idea is most instructive-about the decline of the possibility of the ethical imagination in modern bureaucracies and of the place that rhetoric as a discipline has occupied as actor and victim in that decline.

This first collaboration of mine with Alan exposed me to what I have since come to regard as his particular genius: to be able to see quickly the deeper implication of an idea-to see it in relationship to several spheres of life and to be able to express that significance in a prose that miraculously and dramatically mixes the abstract with the concrete and the perspective of the academy with that of the street.

Our work on the Challenger explosion was the first of several collaborations that Alan and I undertook. The most important for me was our co-editing of the collection Re-Reading Aristotle's Rhetoric. There Alan showed me not only how to create an anthology of critical essays but how to enter into partnership with scholars around a common project. He was the catalyst not only for many of my subsequent publications but also for the work of others in the department as well, who benefitted from Alan's example and guidance. It was a case where hiring a single scholar lifted the collective scholarship of an entire department.

Collaborating with Alan Gross was and is for me a humbling experience. But I am grateful for the opportunity.

\section{Reference List}

Gross, A. G. and A. Walzer. "The Challenger Disaster and the Revival of Rhetoric in Organizational Life." Argumentation 11 (1997): 75-93.

Walzer, A. and A. Gross. "Positivists, Postmodernists, Aristotelians, and the Challenger Disaster." College English 56 (1994): 42033 . 